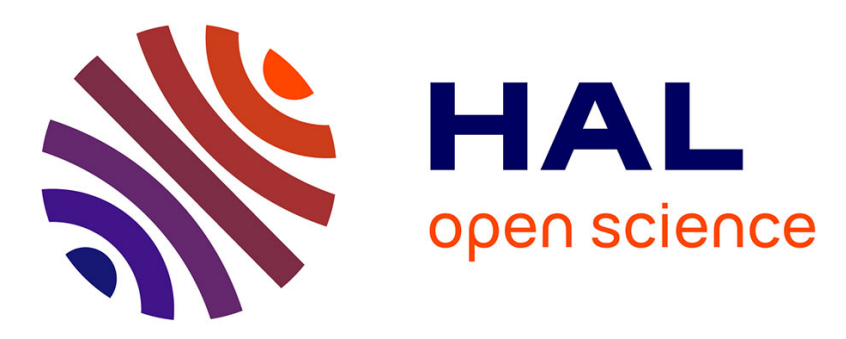

\title{
Epitaxial undoped indium oxide thin films: Structural and physical properties.
}

\author{
Wilfried Seiler, M Nistor, J Perrière, C. Heber
}

\section{To cite this version:}

Wilfried Seiler, M Nistor, J Perrière, C. Heber. Epitaxial undoped indium oxide thin films: Structural and physical properties.. Solar Energy Materials and Solar Cells, 2013, 116, pp.34-42. 10.1016/j.solmat.2013.04.002 . hal-01001724

\section{HAL Id: hal-01001724 https://hal.science/hal-01001724}

Submitted on 3 Jul 2014

HAL is a multi-disciplinary open access archive for the deposit and dissemination of scientific research documents, whether they are published or not. The documents may come from teaching and research institutions in France or abroad, or from public or private research centers.
L'archive ouverte pluridisciplinaire HAL, est destinée au dépôt et à la diffusion de documents scientifiques de niveau recherche, publiés ou non, émanant des établissements d'enseignement et de recherche français ou étrangers, des laboratoires publics ou privés. 


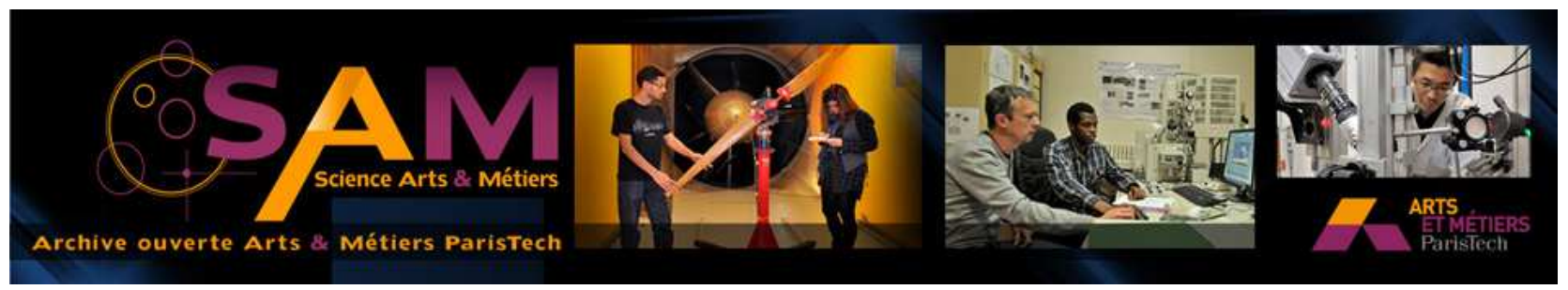

Science Arts \& Métiers (SAM)

is an open access repository that collects the work of Arts et Métiers ParisTech researchers and makes it freely available over the web where possible.

This is an author-deposited version published in: http://sam.ensam.eu

Handle ID: .http://hdl.handle.net/10985/8230

\section{To cite this version :}

Wilfried SEILER, M NISTOR, J PERRIÈRE - Epitaxial undoped indium oxide thin films: Structural and physical properties. - Solar Energy Materials \& Solar Cells - Vol. 116, p.34-42. - 2013 


\title{
Epitaxial undoped indium oxide thin films: Structural and physical properties
}

\author{
W. Seiler ${ }^{\mathrm{a}}$, M. Nistor ${ }^{\mathrm{b}, *}$, C. Hebert $^{\mathrm{c}}$, J. Perrière ${ }^{\mathrm{c}}$ \\ a PIMM, UMR CNRS 8006 Arts et Métiers ParisTech, 151 Boulevard de l'Hopital, 75013 Paris, France \\ ${ }^{\mathrm{b}}$ National Institute for Lasers, Plasma and Radiation Physics (NILPRP), L22 P.O. Box. MG-36, 77125 Bucharest-Magurele, Romania \\ ' Institut des Nanosciences de Paris (INSP), UMR CNRS 7588, Université Pierre et Marie Curie-Paris 6, Place Jussieu, 75252 Paris cedex 05, France
}

\begin{abstract}
A B S T R A C T
Indium oxide thin films were grown by the pulsed electron beam deposition method on c-cut sapphire substrates at $10^{-2}$ mbar oxygen pressure and temperature up to $500{ }^{\circ} \mathrm{C}$. Such conditions lead to the formation of dense, smooth and stoichiometric $\operatorname{In}_{2} \mathrm{O}_{3}$ films, with the cubic bixbyite structure. Epitaxial thin films were obtained at substrate temperatures as low as $200{ }^{\circ} \mathrm{C}$. Pole figure measurements indicate the existence of $(111)$ oriented $\operatorname{In}_{2} \mathrm{O}_{3}$ crystallites with different in-plane symmetry, i.e. three-fold and six-fold symmetry. The origin of this effect may be related to the specificities of the growth method which can induce a large disorder in the oxygen network of $\operatorname{In}_{2} \mathrm{O}_{3}$, leading then to a six-fold symmetry in the (111) plane of the bixbyite structure. This temperature resistivity behaviour shows metallic conductivity at room temperature and a metal-semiconductor transition at low temperature for $\operatorname{In}_{2} \mathrm{O}_{3}$ films grown at $200{ }^{\circ} \mathrm{C}$, while the classical semiconductor behaviour was observed for the films grown at 400 and $500{ }^{\circ} \mathrm{C}$. A maximum mobility of $24.7 \mathrm{~cm}^{2} / \mathrm{V} \mathrm{s}$ was measured at $200{ }^{\circ} \mathrm{C}$, and then it falls off with improving the crystalline quality of films. The optical transparency is high ( $>80 \%)$ in a spectral range from $500 \mathrm{~nm}$ to $900 \mathrm{~nm}$.
\end{abstract}

Keywords:

Indium oxide

Thin films

Optical and electrical properties

\section{Introduction}

Indium oxide $\left(\mathrm{In}_{2} \mathrm{O}_{3}\right)$ is a transparent conducting oxide which presents a high conductivity (free carriers up to $10^{17}-10^{19} \mathrm{~cm}^{-3}$ range) without intentional doping [1], the origin of which is still under debate [2]. Moreover, undoped $\mathrm{In}_{2} \mathrm{O}_{3}$ thin films exhibit conductivities with 4-5 orders of magnitude higher than that of the bulk [3], and recently explained by the presence of surface donors instead of bulk defects. When doped with typically 9 at\% tin oxide, indium-tin oxide (ITO) is one of the most popular transparent conducting electrode used in thin-film photovoltaics, flat-panel display devices, due to the highest transparency for visible light ( $>85 \%$ at wavelengths from 340 to $780 \mathrm{~nm}$ ) combined with the lowest electrical resistivity $\left(7.7 \times 10^{-5} \Omega \mathrm{cm}\right)$ [4]. The recent trend towards higher quality and tailoring transparent conducting electrodes to constraints of specific electronic and solar cell technologies demands the continuous optimisation of $\mathrm{In}_{2} \mathrm{O}_{3}$ thin film properties and processing conditions $[1,2]$.

The formation of $\operatorname{In}_{2} \mathrm{O}_{3}$ thin films has been studied by various methods such as molecular organic chemical vapour deposition [5-8], plasma assisted molecular beam epitaxy [9,10], sputtering [11], atomic layer deposition [12] or pulsed laser deposition [13]. The epitaxial growth of $\mathrm{In}_{2} \mathrm{O}_{3}$ on Y-stabilized $\mathrm{ZrO}_{2}$, c-cut sapphire,

\footnotetext{
* Corresponding author. Tel.: +40 214574490; fax: +40 214574490

E-mail address: mnistor@infim.ro (M. Nistor).
}

InAs or MgO single crystal substrates has been already reported $[4,5,13]$. Whatever the growth methods, the epitaxial film formation was generally carried out at relatively high substrate temperature, i.e. $T>500{ }^{\circ} \mathrm{C}$. However, the crystallisation of $\mathrm{In}_{2} \mathrm{O}_{3}$ can occur at temperatures as low as $150^{\circ} \mathrm{C}$, following previous reports [14] and studies on indium based oxide materials have indicated that optimum materials properties are obtained for substrate temperature in the $200-400{ }^{\circ} \mathrm{C}$ range $[15,16]$. Low growth temperatures are typically required for transparent conducting layers to avoid the degradation of the solar cell junctions. The possibility to obtain $\mathrm{In}_{2} \mathrm{O}_{3}$ films with good structural characteristics, low electrical resistivity (about $10^{-4} \Omega \mathrm{cm}$ ) and high optical transparency ( $>85 \%$ ) on c-cut substrates in the $200-400{ }^{\circ} \mathrm{C}$ range, would open the way to new applications in thin film photovoltaics.

Our first aim in this work was thus to study the growth and properties of indium oxide films in a relatively low temperature domain $\left(T \leq 500{ }^{\circ} \mathrm{C}\right)$, i.e. to determine the nature of the crystalline phase, its texture and eventual epitaxial relationships with single crystal substrate, and to correlate these structural characteristics with the optical and electrical properties of the films. Pulsedelectron beam deposition method (PED) which was already used to grow high quality ITO films [17] has been used for the growth of the indium oxide films. Epitaxial $\mathrm{In}_{2} \mathrm{O}_{3}$ films were thus grown on c-cut sapphire substrates in the $200-500{ }^{\circ} \mathrm{C}$ range, with various epitaxial relationships. The physical (optical and electrical) properties of these films were not related to the crystalline quality of the films, but certainly to the oxygen composition. 


\section{Experimental}

The $\operatorname{In}_{2} \mathrm{O}_{3}$ thin films were grown by pulsed electron beam deposition method (PED) in the experimental setup previously described [17]. The following parameters were used: an external capacitor of $16 \mathrm{nF}$, a high voltage of $14 \mathrm{kV}$, repetition rate $1-2 \mathrm{~Hz}$, $100 \mathrm{~ns}$ full width at half maximum (FWHM) pulse width of the electron beam, fluence of about $2 \mathrm{~J} / \mathrm{cm}^{2}$ and an oxygen pressure of $2 \times 10^{-2}$ mbar. Films with about $50-300 \mathrm{~nm}$ in thickness were grown on c-cut single crystal sapphire substrates under controlled substrate temperature in the room temperature to $500{ }^{\circ} \mathrm{C}$ range. After deposition the films were cooled down at the oxygen pressure used for the growth, or at atmospheric oxygen pressure.

The structural characterizations were carried out by X-ray diffraction (XRD) analyses using a four circle diffractometer (Philips Xpert MRD) with the $\mathrm{Cu} K \alpha$ radiation $(\lambda=0.154 \mathrm{~nm})$ from the PIMM-Arts et Metiers ParisTech in Paris. The nature of the crystalline phases, their axes parameters and their eventual crystallographic textures were investigated in the symmetric Bragg-Brentano geometry. The in-plane epitaxial relationships between the film and the single crystal substrate were studied by asymmetric X-ray diffraction through pole figures measurements.

The resistivity of the $\operatorname{In}_{2} \mathrm{O}_{3}$ films was measured as a function of temperature from room temperature to liquid helium, by the classical four probe method, with ex-situ deposited gold electrodes and wire-bonded contacts. The resistivity and the nature, concentration and mobility of the carriers were determined with a MMR Hall measurement system (in the van der Pauw geometry) at room temperature under a magnetic field of $0.3 \mathrm{~T}$. The transmittance of the films was measured with a spectrophotometer Cary 100 in the wavelength range $190-900 \mathrm{~nm}$.

\section{Results}

The oxygen composition in oxide films plays so far a major role not only on their structural and physical properties [18-20], but also on their nature, i.e. homogeneous or heterogeneous $[17,21]$. Indeed, recent studies have shown that a large oxygen deficiency in indium tin oxide films can lead to the formation of a nanocomposite system with metallic clusters embedded in a stoichiometric matrix [22]. To avoid the formation of such heterogeneous nanocomposite systems, the films were grown by PED under oxygen gas which precludes large oxygen deficiencies. However oxygen vacancies could be present in the films and could play a major role on the electrical conductivity of the $\operatorname{In}_{2} \mathrm{O}_{3}$ films [23].

$\mathrm{In}_{2} \mathrm{O}_{3}$ crystallises in two distinct structures, the bodycentred cubic bixbyite $(a=1.0118 \mathrm{~nm})$ and the rhombohedral ( $a=0.5478 \mathrm{~nm}$ and $c=1.451 \mathrm{~nm}$ ) structure. In our work, all the PED $\mathrm{In}_{2} \mathrm{O}_{3}$ films grown at $T \leq 500{ }^{\circ} \mathrm{C}$ were found to crystallise in the pure bixbyite structure. As a matter of fact, Fig. 1 represents typical diffraction patterns for $\mathrm{In}_{2} \mathrm{O}_{3}$ films grown on c-cut sapphire between 200 and $500{ }^{\circ} \mathrm{C}$. Two peaks located at $30.475^{\circ}$ and $35.455^{\circ}$ can be observed in the diagrams recorded on the film grown at $200{ }^{\circ} \mathrm{C}$. These peaks can be identified with the (222) and (004) family planes of the $\operatorname{In}_{2} \mathrm{O}_{3}$ bixbyite indicating preferential (111) and (001) textures. For increasing growth temperatures up to $500{ }^{\circ} \mathrm{C}$, the (004) peak is no longer observed, the films being highly (111) textured, and the intensity of the (222) peak is an increasing function of the growth temperature.

Considering the surface free energy of formation of the main planes of the $\mathrm{In}_{2} \mathrm{O}_{3}$ bixbyite phase, the (111) texture is expected since the high atomic density (111) plane of the bixbyite presents a lower surface free energy than the polar (001) plane, as it has been previously discussed [24]. The presence of the (001) texture

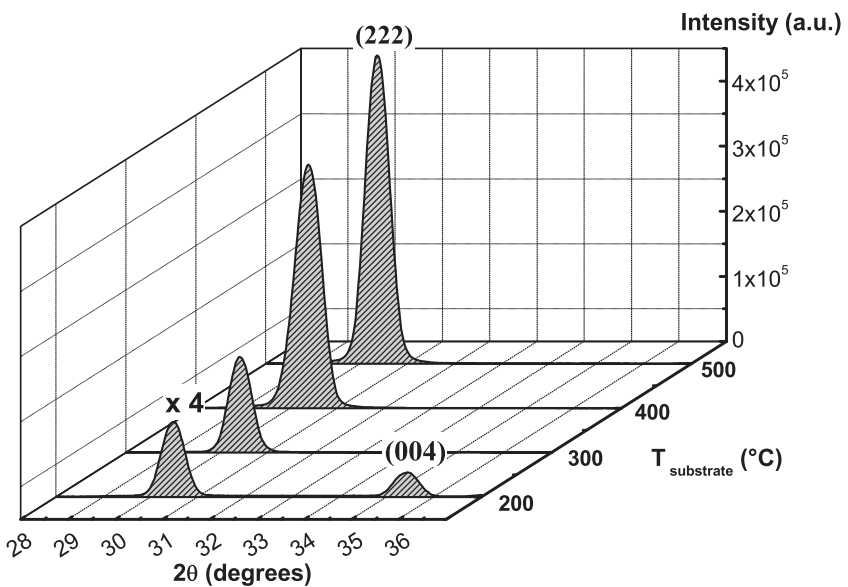

Fig. 1. $\theta-2 \theta$ X-ray diffraction patterns recorded for $\operatorname{In}_{2} \mathrm{O}_{3}$ films grown on c-cut sapphire substrates at $200,300,400$ and $500{ }^{\circ} \mathrm{C}$. The intensity of the patterns of the film grown at $200{ }^{\circ} \mathrm{C}$ is multiplied by a factor of 4 .

Table 1

\begin{tabular}{lcccc}
\hline Temperature $\left({ }^{\circ} \mathbf{C}\right)$ & $\mathbf{2 0 0}$ & $\mathbf{3 0 0}$ & $\mathbf{4 0 0}$ & $\mathbf{5 0 0}$ \\
\hline (222) peak & $30.475^{\circ}$ & $30.415^{\circ}$ & $30.385^{\circ}$ & $30.355^{\circ}$ \\
FWHM peaksize & $0.58^{\circ}$ & $0.57^{\circ}$ & $0.65^{\circ}$ & $0.60^{\circ}$ \\
FWHM rocking curve & $7.5^{\circ}$ & $5^{\circ}$ & $2.3^{\circ}$ & $1.6^{\circ}$ \\
Crystallite size (nm) & 14.2 & 14.4 & 12.6 & 13.7 \\
\hline
\end{tabular}

is a priori unexpected from surface energy considerations, but other parameters like the fact that the c-cut sapphire plane is a polar plane and/or possible epitaxy of the (001) oriented $\operatorname{In}_{2} \mathrm{O}_{3}$ on the c-cut sapphire may play a role (see below).

Table 1 summarises the main insights drawn from these XRD patterns. The $2 \theta$ values of the (222) plane were found lower than the bulk value $\left(30.581^{\circ}\right)$, even more and more lower for increasing growth temperature. The corresponding increase in axis parameter could be due to a slight oxygen deficiency and/or the existence of stresses in the grown films. The crystallite size (coherence length) was estimated from the (222) line width using the Debye-Scherrer formulae, and was found roughly constant as a function of the growth temperature. The FWHM of rocking curves are presented in Table 1 and show decreasing values with increasing growth temperature, which means an increase in the crystalline quality of the $\operatorname{In}_{2} \mathrm{O}_{3}$ films, as it is generally observed.

Despite the high values of the film mosaïcity (see Table 1), the possible epitaxy of the films was checked. Poles figures for the (044) planes of $\operatorname{In}_{2} \mathrm{O}_{3}\left(2 \theta=51.04^{\circ}\right)$ were recorded on films grown between 200 and $500{ }^{\circ} \mathrm{C}$, and are presented in Fig. 2. On these figures three poles located at a declination angle $\psi$ equal to $57.6^{\circ}$ are observed (assigned with the ${ }^{*}$ symbol). They represent the poles of the $(02-24)$ planes of the sapphire substrate, which are observed owing to their diffracting angle $2 \theta\left(52.56^{\circ}\right)$. Such poles allow us to determine the epitaxial relationships between film and substrate. For the film grown at $200{ }^{\circ} \mathrm{C}$, two series of poles are present. Twelve poles are located at a $\psi$ value equal to $45^{\circ}$ (assigned with the @ symbol), i. e. the value expected for the (044) poles of the (001) oriented $\mathrm{In}_{2} \mathrm{O}_{3}$ crystallites. These 12 poles are related to the respective symmetry of the film and substrate $(4 \times 3)$, i.e. four from cubic film and three from the rhomboedral sapphire substrate. In addition, six poles are observed at a $\psi$ value equal to $35.3^{\circ}$ (assigned with the \# symbol), corresponding to the (111) oriented $\mathrm{In}_{2} \mathrm{O}_{3}$ crystallites. This figure also shows that three of these six poles due to (111) oriented crystallites are more intense than the others. 

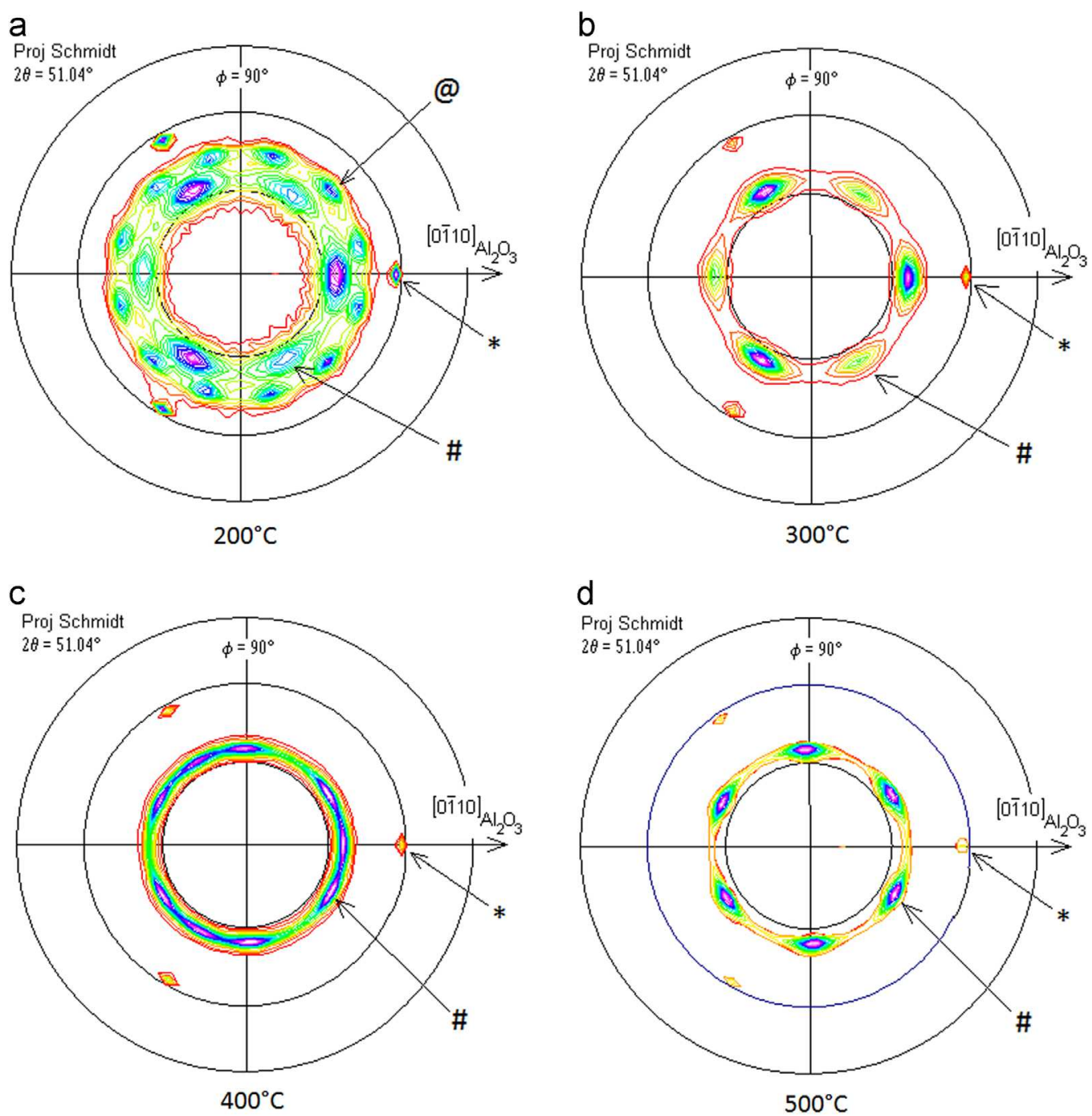

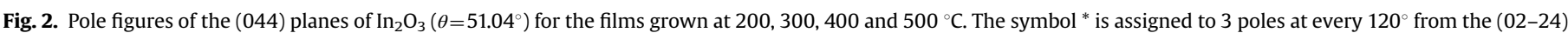

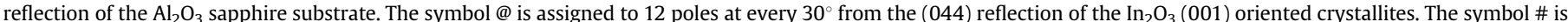
assigned to the poles from the (044) reflection of the $\mathrm{In}_{2} \mathrm{O}_{3}(111)$ oriented crystallites.

The respective azimuthal positions of the poles of the (044) $\mathrm{In}_{2} \mathrm{O}_{3}$ and three $(02-24)$ sapphire poles lead to the following in-plane epitaxial relationships:

$$
\begin{aligned}
& {[1-10]_{\mathrm{In}_{2} \mathrm{O}_{3}} \|[1-210]_{\mathrm{Al}_{2} \mathrm{O}_{3}} \text { and }[1-10]_{\mathrm{In}_{2} \mathrm{O}_{3}} \|[0-110]_{\mathrm{Al}_{2} \mathrm{O}_{3}}} \\
& \text { for the (001) } \mathrm{In}_{2} \mathrm{O}_{3} \text { crystallites }
\end{aligned}
$$$$
[1-10]_{\operatorname{In}_{2} \mathrm{O}_{3}} \|[1-210]_{\mathrm{Al}_{2} \mathrm{O}_{3}} \text { for the (111) } \operatorname{In}_{2} \mathrm{O}_{3} \text { crystallites }
$$

With the respective in-plane parameters of hexagon and square unit of the two lattices $(0.476 \mathrm{~nm}$ for the sapphire and $1.0118 \mathrm{~nm}$ for $\mathrm{In}_{2} \mathrm{O}_{3}$ ), a very significant lattice mismatch is deduced. However, the specific orientations of the films, can be explained in the frame of the domain matching epitaxy or extended atomic distance mismatch approach [5,25], in which "m" lattice units of the film match with "p" lattice units of the substrate. The values of $m$ and $p$ are defined as the minimum integers which satisfy the following relation:

$\mathrm{md}_{\mathrm{f}} \approx \mathrm{p} d_{\mathrm{s}}$ or $\left[d_{\mathrm{f}} / d_{\mathrm{s}}\right] \approx[\mathrm{p} / \mathrm{m}]$

$d_{\mathrm{f}}$ and $d_{\mathrm{s}}$ being the respective atomic distances in the film and substrate parallel directions. The corresponding lattice mismatch $\delta$ can thus be defined by [26]:

$\delta=2\left[\mathrm{md} d_{\mathrm{f}}-\mathrm{p} d_{\mathrm{s}}\right] /\left[\mathrm{m} d_{\mathrm{f}}+\mathrm{p} d_{\mathrm{s}}\right]$

Table 2 summarises the results of this analysis through the matching relationship and lattice mismatch. This table shows that the [1-10] $\mathrm{In}_{2} \mathrm{O}_{3}$ direction plays a major role in the epitaxial growth as this direction is present in the epitaxial relationships for both (001) and (111) $\mathrm{In}_{2} \mathrm{O}_{3}$ epitaxy. As a result the matching relationships and lattice mismatch (Table 2) are the same for (001) and (111) epitaxy. This could at least partly, at the origin of the presence of the (001) $\mathrm{In}_{2} \mathrm{O}_{3}$ texture in the film grown at $200{ }^{\circ} \mathrm{C}$. At higher temperature the surface mobility of the atoms increases and can lead to the formation of the most energetically favourable texture, i.e. the (111) $\operatorname{In}_{2} \mathrm{O}_{3}$ texture.

For the pole figures recorded on films grown at $T>200{ }^{\circ} \mathrm{C}$, the poles due to the (001) oriented $\operatorname{~}_{2} \mathrm{O}_{3}$ crystallites are no longer present, in agreement with the XRD diagrams (Fig. 1). Six poles due to (111) oriented $\mathrm{In}_{2} \mathrm{O}_{3}$ crystallites are observed at 300 and $500{ }^{\circ} \mathrm{C}$ growth temperature. The azimuthal positions of the six poles observed at $300{ }^{\circ} \mathrm{C}$ are identical to those observed at $200{ }^{\circ} \mathrm{C}$, while the six poles observed at $500{ }^{\circ} \mathrm{C}$ are rotated by $30^{\circ}$. The following epitaxial relationships are therefore deduced:

$[1-10]_{I_{2} \mathrm{O}_{3}} \|[1-210]_{\mathrm{Al}_{2} \mathrm{O}_{3}}$ for the (111) $\operatorname{In}_{2} \mathrm{O}_{3}$ crystallites at $300{ }^{\circ} \mathrm{C}$ $[1-10]_{\operatorname{In}_{2} \mathrm{O}_{3}} \|[1-110]_{\mathrm{Al}_{2} \mathrm{O}_{3}}$ for the (111) $\operatorname{In}_{2} \mathrm{O}_{3}$ crystallites at $500{ }^{\circ} \mathrm{C}$

The corresponding matching relationships and lattice mismatch are given in Table 2. In the case of the film grown at $400{ }^{\circ} \mathrm{C}$, the pole figure shows nine poles, i.e. three series of three 
Table 2

\begin{tabular}{|c|c|c|c|}
\hline Texture & In-plane orientation & Matching relationships & Lattice mismatch (\%) \\
\hline (001) & $\begin{array}{l}{[1-10]_{\mathrm{In}_{2} \mathrm{O}_{3}} \|[1-210]_{\mathrm{Al}_{2} \mathrm{O}_{3}}} \\
{[1-10]_{\mathrm{In}_{2} \mathrm{O}_{3}} \|[0-110]_{\mathrm{Al}_{2} \mathrm{O}_{3}}}\end{array}$ & $\begin{array}{l}d_{\mathrm{f}} \approx 3 d_{\mathrm{s}}\left(d_{\mathrm{f}}=1.4308 \mathrm{~nm} ; d_{\mathrm{s}}=0.4 .759 \mathrm{~nm}\right) \\
4 d_{\mathrm{f}} \approx 7 d_{\mathrm{s}}\left(d_{\mathrm{f}}=1.4308 \mathrm{~nm} ; d_{s}=0.8242 \mathrm{~nm}\right)\end{array}$ & $\begin{array}{l}\delta=0.217 \\
\delta=0.803\end{array}$ \\
\hline (111) & $\begin{array}{l}{[1-10]_{\mathrm{In}_{2} \mathrm{O}_{3}} \|[1-210]_{\mathrm{Al}_{2} \mathrm{O}_{3}}} \\
{[1-10]_{\mathrm{In}_{2} \mathrm{O}_{3}} \|[0-110]_{\mathrm{Al}_{2} \mathrm{O}_{3}}}\end{array}$ & $\begin{array}{l}d_{\mathrm{f}} \approx 3 d_{\mathrm{s}}\left(d_{\mathrm{f}}=1.4308 \mathrm{~nm} ; d_{\mathrm{s}}=0.4 .759 \mathrm{~nm}\right) \\
4 d_{\mathrm{f}} \approx 7 d_{\mathrm{s}}\left(d_{\mathrm{f}}=1.4308 \mathrm{~nm} ; d_{\mathrm{s}}=0.8242 \mathrm{~nm}\right)\end{array}$ & $\begin{array}{l}\delta=0.217 \\
\delta=0.803\end{array}$ \\
\hline
\end{tabular}

a

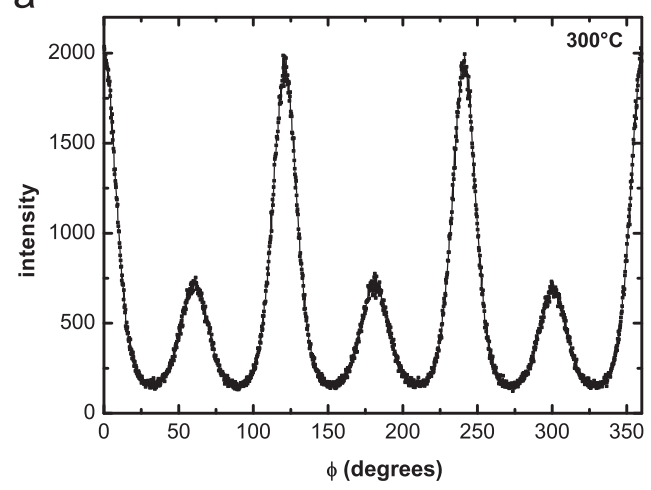

$b$

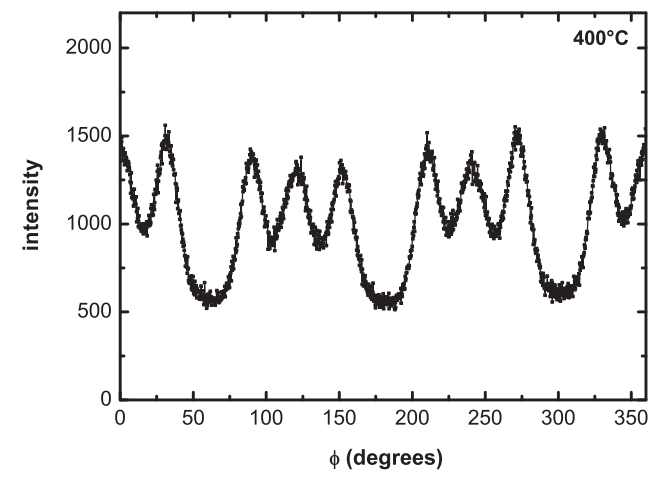

C

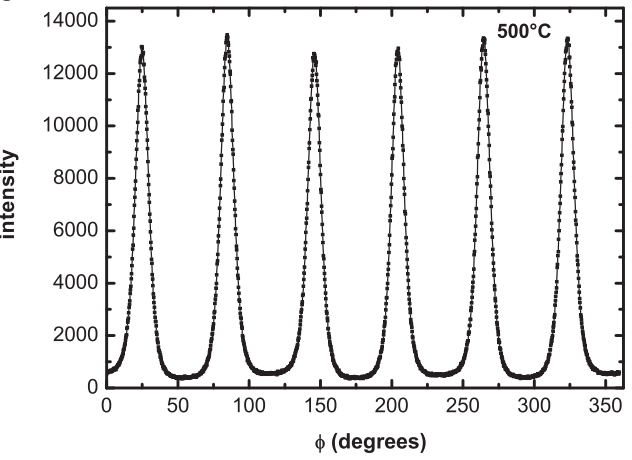

Fig. 3. (044) $\Phi$-scan profile for the $\mathrm{In}_{2} \mathrm{O}_{3}$ films grown at (a) $300{ }^{\circ} \mathrm{C}$, (b) $400{ }^{\circ} \mathrm{C}$ and (c) $500{ }^{\circ} \mathrm{C}$.

poles. Such a pole figure seems schematically to correspond to the superposition of the pole figures observed at 300 and $500{ }^{\circ} \mathrm{C}$.

The fact that the 6 poles corresponding to the (111) oriented crystallites observed at 200 and $300{ }^{\circ} \mathrm{C}$ are not equivalent (three of them present a higher intensity) has to be commented. Indeed, taking into account the 3-fold symmetry of the (0001) plane of the sapphire substrate, and the 3-fold symmetry of the (111) planes of the cubic bixbyite structure, only 3 poles should be present, while 6 are observed in Fig. 2. The presence of six poles has been previously observed in various oxide films grown on c-cut sapphire substrate and has been explained by the real surface of the ccut sapphire which is usually stepped, leading to unconventional number of variants in epitaxial films [27]. Moreover, previous studies of the epitaxial growth of cubic $\operatorname{In}_{2} \mathrm{O}_{3}$ (111) on c-cut sapphire substrates reported poles figures or phi scans showing a six-fold symmetry and discrete peaks $[8,9,11]$. These results were interpreted by the existence of two different symmetry-equivalent twinned crystal orientations shifted by $60^{\circ}$. High resolution TEM images on indium based oxide films grown on c-cut sapphire substrates were recorded showing the domain boundary of such twin crystals $[9,12]$.

In these preceding cases, the intensity of the poles or peaks in phi scans was similar, while in our work a drastic difference is observed. Indeed, three poles in Fig. 2a, show a larger intensity, and this was checked by the measurement of a phi scan at a $35.3^{\circ}$ declination angle which is presented in Fig. 3a. Three of the peaks present a larger intensity and a slightly lower width. On the contrary the phi scan corresponding to the $500{ }^{\circ} \mathrm{C}$ growth temperature (Fig. 3c) shows 6 peaks with the same intensity, shifted by a $30^{\circ}$ angle with respect to Fig. 3a. Fig. 3b which corresponds to the film grown at $400{ }^{\circ} \mathrm{C}$ seems to be roughly the sum of the two phi scans presented in Fig. 3a and c.

Such results cannot be explained by defects on the sapphire substrates or presence of twin crystal in the films, which would lead to equivalent intensity and FWHM for the poles or peaks. The origin of these differences has been related to the presence of two kinds of (111) $\mathrm{In}_{2} \mathrm{O}_{3}$ oriented crystallites in the films, i.e. crystallites with different in-plane symmetry: three-fold and six-fold symmetry.

Let us recall that in the bixbyite structure, indium atoms are located on two non-equivalent sites and that $25 \%$ of the oxygen sites are not occupied. This leads to a specific arrangement of "constitutional" oxygen vacancies network, along the body diagonal and face diagonal of the cubic cell [28]. In this bixbyite structure, this arrangement leads to a three-fold symmetry in the (111) plane. However, if some disorder is introduced in the network of "constitutional" oxygen vacancies (random distribution of the vacancies in the plane), the three-fold symmetry is no longer preserved, and a six-fold symmetry will appear in the (111) plane as it is the case in the fluorite structure [28]. We can thus 
assume that in the low temperature range, the film growth leads to the formation of both ordered bixbyite crystallites with a threefold symmetry, and disordered bixbyite crystallites with a six-fold symmetry. Such an assumption can explain the pole figure presented in Fig. 2a. For $T=500{ }^{\circ} \mathrm{C}$, the six poles present in the pole figure show the same intensity (as it can be checked on the phi scan presented in Fig. 3c), meaning that a sole phase is present, i.e. the disordered bixbyite phase with a six-fold symmetry in the (111) plane. In this frame, the pole figure recorded on the film grown at $400{ }^{\circ} \mathrm{C}$ corresponds to the transition from the low temperature (both ordered and disordered bixbyite) to high temperature (only disordered bixbyite) behaviour.

The transition temperature from ordered to disordered bixbyite structure depends upon the film growth rate. Indeed, growth rates as high as $1 \mathrm{~nm}$ per pulse can be obtained by PED, thanks to the high efficiency of energy transfer from incident polyenergetic (up to $15 \mathrm{keV}$ ) electrons to the target. In the case of a very high deposition rate, the pole figure recorded on a film grown at $500{ }^{\circ} \mathrm{C}$ with such a high growth rate (Fig. 4a) is similar to that presented in Fig. 2c, with three series of three poles. This point can be checked on the corresponding phi scan presented in Fig. 4b. It follows that at least two experimental parameters play a role on the nature (ordered or disordered) of bixbyite phase which can be grown: the substrate temperature and the deposition rate which is related to the flux of incident species coming from the target.

The physical properties of the films grown between 200 and $500{ }^{\circ} \mathrm{C}$ were studied and Fig. 5 shows their transmittance in the $300-900 \mathrm{~nm}$ range. All the films are transparent, with values of the transmittance between $80 \%$ and $85 \%$ over $500 \mathrm{~nm}$, including that of the double polished c-cut sapphire substrate. The absorption coefficient $(\alpha)$ was calculated using the relation $\alpha=(1 / d) \ln [(1$ $-R) / T$, where $T$ is the transmittance, $R$ is the reflectance (neglected here) and $d$ is the film thickness. The values of the direct optical band gap $\left(E_{\mathrm{g}}\right)$ were determined from absorption coefficient data by the extrapolating the linear part of the fundamental absorption edge to the energy axis (Tauc's plot, i.e. $(\alpha E)^{2}$ vs. $E$, where $E$ is the photon energy) and are presented in the Table 3, together with the results of the Hall effect measurements at room temperature. As example, in the inset of Fig. 5, is shown the Tauc plot for film grown at $500{ }^{\circ} \mathrm{C}$. The direct optical band gap values are varying slightly with substrate temperature, being lower than value of $3.75 \mathrm{eV}$, typically reported in previous studies $[1,2,5,8]$. The value of $\mathrm{In}_{2} \mathrm{O}_{3}$ direct electronic band gap was recently revised to be $\leq 3 \mathrm{eV}$ [29] and the low-energy tail which is seen below the absorption edge (Fig. 5) and which was previously attributed to indirect optical transitions, was found to be due to dipole forbidden transitions [29-31].

In Table 3 the values of carrier mobility are similar in the $\operatorname{In}_{2} \mathrm{O}_{3}$ films grown at 200 and $300{ }^{\circ} \mathrm{C}$, while the crystalline quality of the films (estimated through the FWHM rocking curves) increases with temperature. A further increase in growth temperature leads to a large decrease in mobility while at the same time the XRD results indicate a further increase in crystalline quality. This demonstrates that the mobility in these $\operatorname{In}_{2} \mathrm{O}_{3}$ films is not dominated by the scattering at grain boundaries or on structural defects as it has been concluded for films grown on YSZ [32]. Indeed, indium oxide is known to exhibit high mobility in the amorphous state which contrasts with the classical observation on Si or other semiconductors [33], i.e. its mobility does not depend on the its structure $[3,34]$.

In order to try to correlate the electrical and structural properties of films, the fraction of ordered bixbyite phase in $\operatorname{In}_{2} \mathrm{O}_{3}$ epitaxial films was estimated from the phi scans presented in Fig. 3. Actually, Fig. 6 shows the variation of the electrical resistivity $(\rho)$, carrier density $(n)$ and fraction of ordered to disordered bixbyite phase $(f)$ as a function of growth temperature. Electrical properties of $\operatorname{In}_{2} \mathrm{O}_{3}$ films grown at room temperature and $120^{\circ} \mathrm{C}$ were added to data already presented in Table 3 . In the

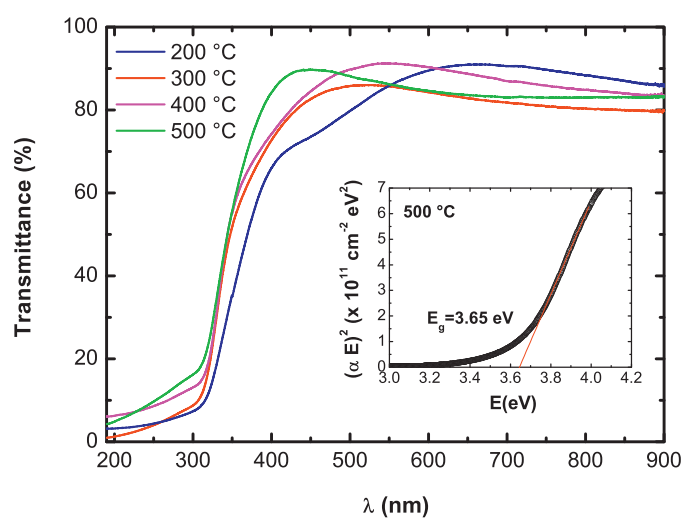

Fig. 5. Optical transmittance of the $\mathrm{In}_{2} \mathrm{O}_{3}$ films grown on transparent c-cut sapphire single crystal substrates at $200,300,400$ and $500{ }^{\circ} \mathrm{C}$. a

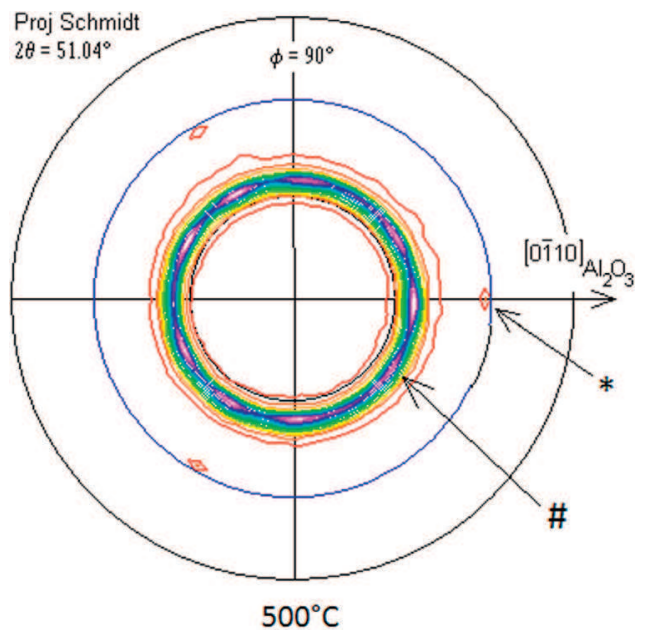

b

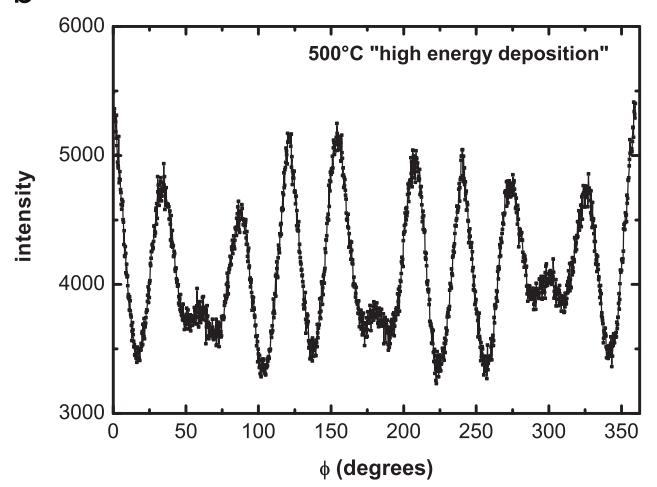

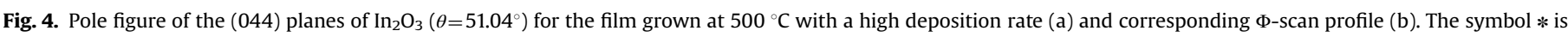

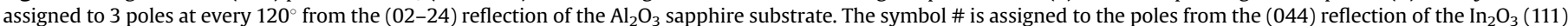
oriented crystallites. 
200-300 ${ }^{\circ} \mathrm{C}$ range the resistivity shows a shallow minimum, while in the same temperature range the estimated fraction of ordered bixbyite phase is roughly constant and maximum. Moreover, the comparison of the variation of the carrier density and fraction of ordered bixbyite phase shows behaviour roughly similar in the $200-300{ }^{\circ} \mathrm{C}$ range. This fact would mean that the ordered bixbyite phase favours a high carrier density and accordingly a lower resistivity. The reason why the ordered bixbyite phase would play this role on the transport properties is not yet clear, but the Fig. 6 indicates a correlation (in the $200-300{ }^{\circ} \mathrm{C}$ range) between the structural characteristics of the $\mathrm{In}_{2} \mathrm{O}_{3}$ films and their transport properties.

Another important point is the large difference in the mobility and carrier concentration of films grown at $300{ }^{\circ} \mathrm{C}$ but with different cooling process (at growth pressure or at atmospheric oxygen pressure). In fact, the cooling down under atmospheric oxygen pressure leads to a large decrease in the carrier concentration and mobility with respect to the measured values in the film cooled down under $2 \times 10^{-2}$ mbar (Table 3 ). This is certainly in relation with the oxygen uptake during this cooling down and a slight difference in the oxygen vacancies density in these two films. As a result large changes in the carrier density could occur due to the cooling down process.

The temperature dependent resistivity curves $R(T)$ were measured for $\mathrm{In}_{2} \mathrm{O}_{3}$ thin films grown by PED in oxygen at various temperatures. Fig. 7 summarises the results through the resistivity curves for films grown in the range $200-400{ }^{\circ} \mathrm{C}$. Depending on the growth temperature and cooling process, these curves show either a semiconducting $\left(400{ }^{\circ} \mathrm{C}\right.$ and $300{ }^{\circ} \mathrm{C}$ cooled under atmospheric oxygen pressure) or a metallic $\left(200{ }^{\circ} \mathrm{C}\right.$ and $300{ }^{\circ} \mathrm{C}$ cooled at $2 \times 10^{-2}$ mbar) behaviour, in relation with the carrier densities given in Table 3. Actually, the critical carrier density for the onset of metallic conductivity as given by the Mott criterion [35] is estimated to be $7.21 \times 10^{18} \mathrm{~cm}^{-3}$ for $\operatorname{In}_{2} \mathrm{O}_{3}$ [10]. Above this value the $\mathrm{In}_{2} \mathrm{O}_{3}$ degenerates, as observed for the $\mathrm{In}_{2} \mathrm{O}_{3}$ films grown at 200 and $300{ }^{\circ} \mathrm{C}$, in correlation with the resistivity-temperature curves (Fig. 7), while films grown at 400 and $500{ }^{\circ} \mathrm{C}$ have values below this limit.

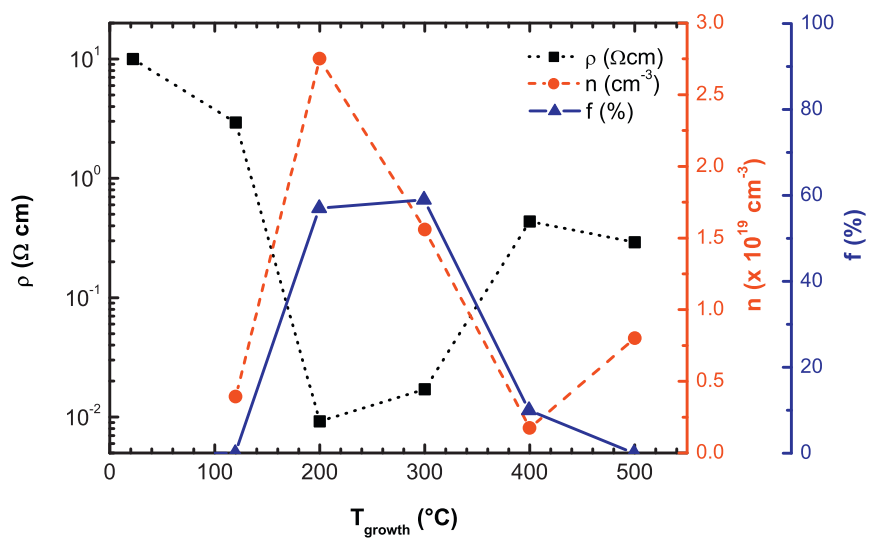

Fig. 6. Electrical resistivity $(\rho)$, carrier density $(n)$ and fraction of ordered to disordered bixbyite phase (f) as a function of growth temperature.
The resistivity curve for the films grown at $400{ }^{\circ} \mathrm{C}$ shows a semiconductor behaviour (Fig. 7) in the whole temperature range, with a negative temperature coefficient resistance (TCR). A thermally activated transport mechanism can be deduced from the Arrhenius plot (Fig. 8d), with the linear variation of $\ln \rho$ with $T^{-1}$ in the 295-213 $\mathrm{K}$ range. The activation energy estimated from the slope is about $31 \mathrm{meV}$. For lower temperatures, an increase of the resistivity and a curvature in the Arrhenius plot are observed. This feature is frequently observed for semiconductor oxides [20], and is generally interpreted by the localisation of carriers which can be described by the variable range hopping (VRH) mechanism [35]. The resistivity can be described by the following relationships:

$\rho(T)=\rho_{0} \exp \left(T_{0} / k T\right)^{1 / 4}$

In that case, $\ln \rho(T)$ follows a linear dependence in $T^{-1 / 4}$ for a three dimensional hopping. Such behaviour which can be observed in the inset of Fig. $8 \mathrm{~d}$, was systematically observed in the $\mathrm{In}_{2} \mathrm{O}_{3}$ films grown at $T>400{ }^{\circ} \mathrm{C}$.

For the films grown at $300{ }^{\circ} \mathrm{C}$, although a negative TCR is observed in Fig. 8b and c, an important difference in the $R(T)$ curves was observed depending upon the cooling process. Indeed, for the film cooled down under atmospheric oxygen pressure (Fig. 8c) the ratio of resistivity between $4 \mathrm{~K}$ and $300 \mathrm{~K}$ is equal to 44 , i.e. a value of the order of those observed in oxide semiconductors $(>20)$, while a value equal to 1.15 is deduced from the Fig. 8b for the film cooled down under growth oxygen pressure $\left(2 \times 10^{-2}\right.$ mbar $)$.

The Arrhenius plot shown in the inset of Fig. $8 \mathrm{c}$ for the films cooled under atmospheric oxygen pressure shows a linear variation of $\ln \rho(T)$, characteristic of a thermally assisted transport mechanism from 293 to $192 \mathrm{~K}$, with activation energy equal to $49 \mathrm{meV}$. On the contrary such an analysis for the curve of Fig. 8b $\left(\mathrm{In}_{2} \mathrm{O}_{3}\right.$ films cooled down under growth oxygen pressure) does not show a linear behaviour on a noticeable temperature range. Thus change in the oxygen pressure during the cooling pressure which could lead to a change in the oxygen composition, i.e. in the oxygen vacancies concentration, leads to a drastic change in the transport phenomena of indium oxide films.

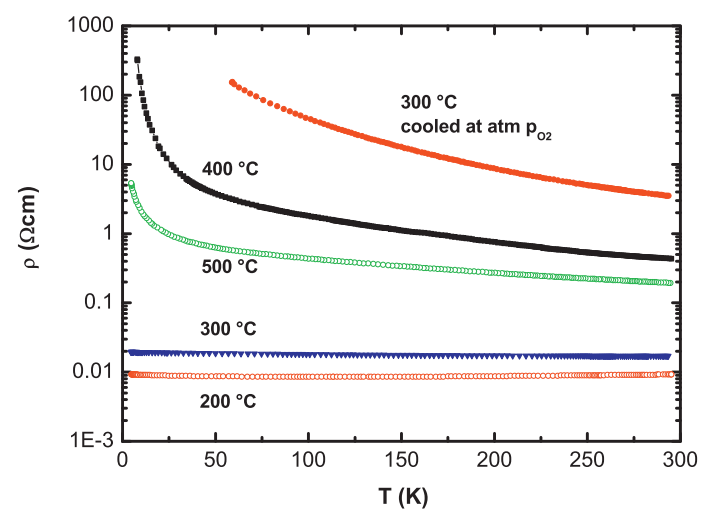

Fig. 7. Electrical resistivity curves as a function of temperature for the $\operatorname{In}_{2} \mathrm{O}_{3}$ films grown at $200,300,400,500{ }^{\circ} \mathrm{C}$ and $300{ }^{\circ} \mathrm{C}$ under cooling at atmospheric $\mathrm{PO}_{2}$.

Table 3

\begin{tabular}{|c|c|c|c|c|c|}
\hline Temperature $\left({ }^{\circ} \mathrm{C}\right)$ & 200 & 300 & 400 & $500 \mathrm{C}$ & 300 cooled at atmospheric po2 \\
\hline Thickness (nm) & 130 & 105 & 99.5 & 85 & 71 \\
\hline Resistivity ( $\Omega$ cm) & $9.198 \times 10^{-3}$ & $1.711 \times 10^{-2}$ & 0.435 & 0.292 & 3.501 \\
\hline Mobility $\left(\mathrm{cm}^{2} / \mathrm{V} \mathrm{s}\right)$ & $24.70 \pm 0.7$ & $23.37 \pm 4$ & $8.27 \pm 1.7$ & $2.67 \pm 0.6$ & $3.17 \pm 2.1$ \\
\hline Carrier Density $\left(\mathrm{cm}^{-3}\right)$ & $2.75 \times 10^{19}$ & $1.56 \times 10^{19}$ & $1.73 \times 10^{18}$ & $8.00 \times 10^{18}$ & $3.68 \times 10^{18}$ \\
\hline$E_{\text {gap }}(e V)$ & 3.55 & 3.69 & 3.66 & 3.65 & 3.64 \\
\hline
\end{tabular}


a

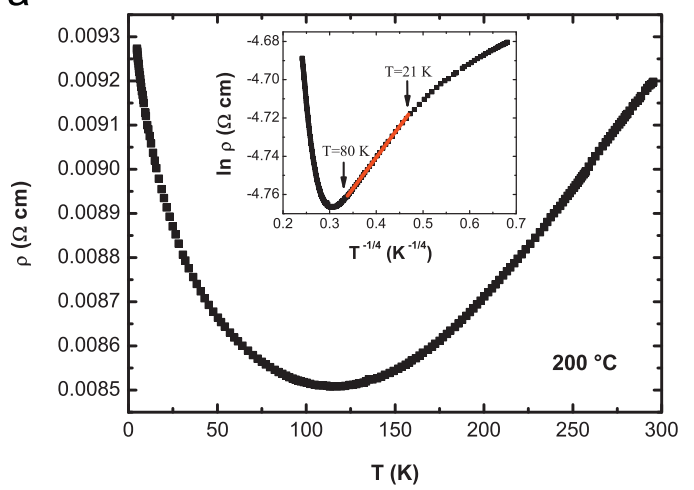

C

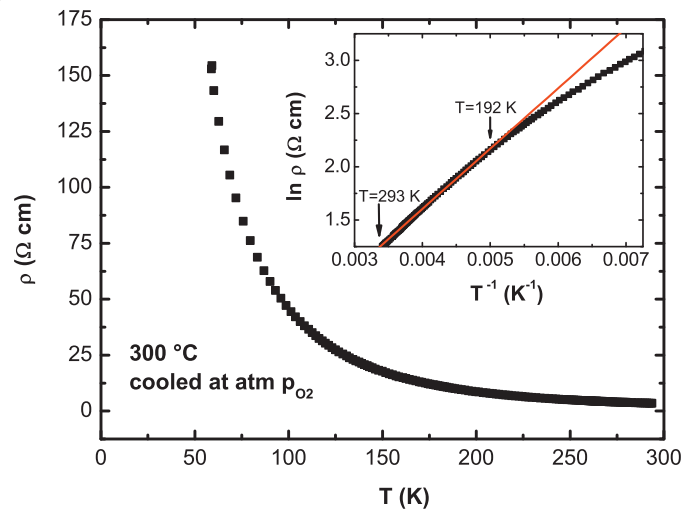

b

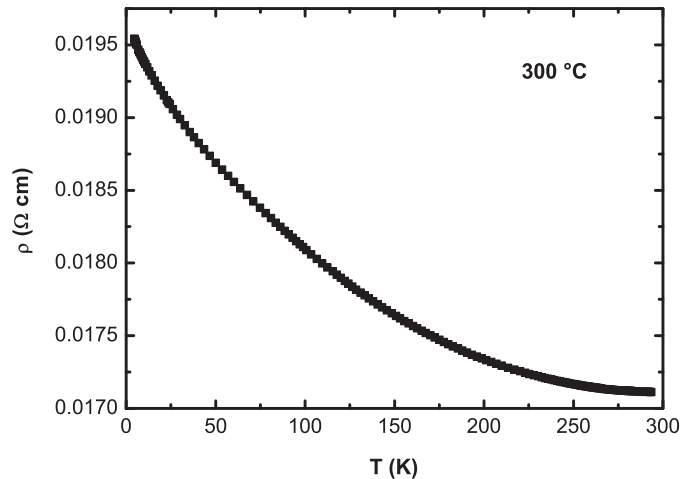

d

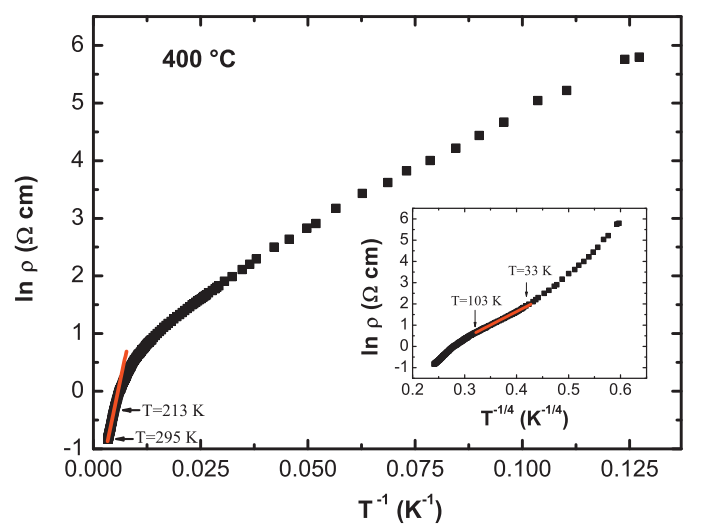

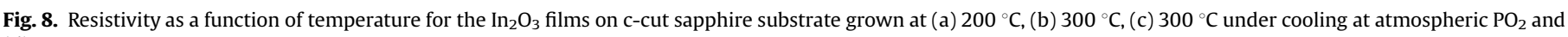
(d) $400{ }^{\circ} \mathrm{C}$.

For the films grown at $200{ }^{\circ} \mathrm{C}$ (Fig. 8a), the $\rho(T)$ curve shows a change of TCR around $118 \mathrm{~K}$. In fact from room temperature down to $118 \mathrm{~K}$ a positive TCR (metallic conductivity) is observed, followed at lower temperatures by a negative TCR, i.e. a metalsemiconductor transition (MST) occurs in the film around $118 \mathrm{~K}$. MST has been already observed in pure [36] or doped In oxide films [37] and in pure [38] or doped Zn oxide films [39]. In these cases the MST was generally analysed in the frame of the quantum corrections to conductivity (QCC) in a disordered conductor [40]. This model used to describe the resistivity curve is considered to be valid provided that the quantum corrections are much smaller than the Boltzmann conductivity at the transition temperature [41]. It must be noticed that the variation of resistivity in Fig. 8a between 118 and $5 \mathrm{~K}$ is about 9\%, i.e. a variation which seems to be too high to explain this MST via the model of quantum corrections to conductivity which has been used in some cases [38,41]. A more plausible approach would be based on the phenomenon of carrier localisation inducing a metal semiconductor transition at low temperature $[35,40]$. In that case, the low temperature resistivity is generally interpreted by Eq. (1) as Mott's variable-range hopping (VRH) caused by localised states in a disordered oxide films [35,42].

The inset of the Fig. 8a represents the variation of $\ln \rho$ as a function of $T^{-1 / 4}$, and a linear variation is observed in the $21-82 \mathrm{~K}$ temperature range. This result is very similar to that recently reported in the case of single crystalline $\mathrm{In}_{2} \mathrm{O}_{3}$ nanowires [42]. In this frame, the carrier localisation at the origin of the MST would be due to the structural disorder in the $\operatorname{In}_{2} \mathrm{O}_{3}$ films grown at $200{ }^{\circ} \mathrm{C}$. Indeed, as noted above, the crystalline quality of this low temperature grown film is lower than those obtained in the films grown at higher temperatures. Let us notice that recently it has been reported that such a $T^{-1 / 4}$ variation for $\ln \rho(T)$ could be interpreted in the frame of a percolation conduction model [43], in the case of studies on carrier transport mechanisms in disordered oxide semiconductors (crystalline and amorphous In-Ga-Zn-oxides). However, the use of such an interpretation for epitaxial films on c-cut sapphire substrates seems questionable.

\section{Discussion}

Specific structural characteristics of the $\mathrm{In}_{2} \mathrm{O}_{3}$ films grown on sapphire substrates reported here have to be discussed. Indeed, the preferential formation of the bixbyite $\operatorname{In}_{2} \mathrm{O}_{3}$ phase (with the three fold symmetry in the (111) plane) is observed for growth $T$ lower than $300{ }^{\circ} \mathrm{C}$, while at higher $T$, a disordered bixbyite phase (with a six fold symmetry in the (111) plane) is present. Moreover, the epitaxial growth of (111) $\operatorname{In}_{2} \mathrm{O}_{3}$ on sapphire substrate corresponds to an "hexagon on hexagon" growth for $T \leq 300{ }^{\circ} \mathrm{C}$, while at higher temperatures, the epitaxial relationship corresponds to a $30^{\circ}$ rotation of the $\mathrm{In}_{2} \mathrm{O}_{3}$ hexagon with respect to the $\mathrm{Al}_{2} \mathrm{O}_{3}$ hexagon. There is a clear effect of the growth temperature on these facts, but some specificity of the PED growth methods have to be taken into account to explain these results.

First in PED, the kinetic energy of the species emitted by the target is high, typically of the order of $50-100 \mathrm{eV}$. Such high energy species will present a high mobility at the surface of the growing film which could favour the formation of crystalline

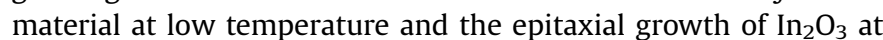
temperature as low as $200{ }^{\circ} \mathrm{C}$. Such a high kinetic energy could be also the reason of the presence of the disordered $\mathrm{In}_{2} \mathrm{O}_{3}$ bixbyite for growth $T<300{ }^{\circ} \mathrm{C}$. Indeed, the bombardment by the species coming from the target could induce oxygen vacancy creation and migration in the near surface region of the bixbyite film. 
This would destroy the organisation of the "constitutional oxygen vacancies" of the bixbyite phase and lead to the formation of the disordered bixbyite phase with the six fold symmetry in the (111) plane of this phase.

For increasing temperatures $\left(T \geq 300^{\circ} \mathrm{C}\right)$, the migration of oxygen vacancies at the surface of the bixbyite phase will be easier and accordingly a random distribution of these vacancies in the (111) plane will lead to the increasing formation of the disordered bixbyite phase. As a result, at $T=500{ }^{\circ} \mathrm{C}$, this disordered bixbyite phase is solely present in the $\operatorname{In}_{2} \mathrm{O}_{3}$ films.

The temperature will play an important role on the precise epitaxial relationships between the $\mathrm{In}_{2} \mathrm{O}_{3}$ film and c-cut sapphire substrate. For $T \leq 300{ }^{\circ} \mathrm{C}$, the epitaxial relationships correspond to the "hexagon on hexagon" growth, which is not the most likely in terms of energy. Indeed, in this configuration as noted previously the In ions from the films and $\mathrm{O}$ ions of the substrate do not coincide optimally [5]. On the contrary, in the case of the other epitaxial relationship ( $30^{\circ}$ rotation of the film hexagon):

$[1-10]_{\operatorname{In}_{2} \mathrm{O}_{3}} \|[0-101]_{\mathrm{Al}_{2} \mathrm{O}_{3}}$

The In ions are into a good coincidence with the $\mathrm{O}$ ions of the substrates, leading to a lower interfacial energy which would favour this configuration [5]. However, with the first epitaxial relationship (hexagon on hexagon), the minimum size of the epitaxial domain, which is deduced from the lattice matching, is rather limited $(1.4038 \mathrm{~nm}$ as deduced from Table 2$)$, while the corresponding minimum size of the domain in the other epitaxial relationship is much higher, $5.7232 \mathrm{~nm}$. As a result, for $T \leq 300{ }^{\circ} \mathrm{C}$, the diffusion of the incident species at the surface of the growing film will be limited and the low size epitaxial domain will be favoured in these conditions, i.e. the $[1-10]_{\left[_{2} \mathrm{O}_{3}\right.} \|[1-210]_{\mathrm{Al}_{2} \mathrm{O}_{3}}$ epitaxial relationship will be observed. For increasing temperature, the incident species could diffuse on longer distances and therefore the formation of an extended epitaxial domain will occur, i.e. the $[1-10]_{\mathrm{In}_{2} \mathrm{O}_{3}} \|[0-110]_{\mathrm{Al}_{2} \mathrm{O}_{3}}$ epitaxial relationship will be thus favoured. It is worth noticing that such a situation corresponds to limited deposition rate. Indeed for large value of deposition rate ( $1 \mathrm{~nm}$ per pulse) the high flux of species on the film surface will "quench" at least partly the film structure, as atoms will not have sufficient time to migrate at the film surface. As a result the bixbyite and disordered bixbyite phases would be observed even at $T=500{ }^{\circ} \mathrm{C}$, as reported in Fig. 3 .

The study of the transport properties of the indium oxide films grown in this work clearly demonstrates that the crystalline quality of the films is not the main parameter governing their physical properties. Actually we only observed a correlation between the presence of the ordered bixbyite phase and the carrier density in the films. Otherwise, the results showed that the highest conductivities are obtained in films grown at the lower temperature $\left(200{ }^{\circ} \mathrm{C}\right)$, corresponding to films presenting different textures, i.e. a lower crystalline quality. A maximum mobility of $24.7 \mathrm{~cm}^{2} / \mathrm{V} \mathrm{s}$ was measured at $200{ }^{\circ} \mathrm{C}$, and then it falls with improvement in the crystalline quality of films. On the contrary, the main parameter which seems to determine the transport properties of these films is their oxygen composition, i.e. the density of oxygen vacancies in the films. A decrease of the concentration of oxygen vacancies acting as electron donors leads to an increase of the resistivity. The variation of the carrier density changes $\mathrm{In}_{2} \mathrm{O}_{3}$ from degenerate to non-degenerate films.

As it has been noted, even the simple change in the cooling atmosphere for a film grown at $300{ }^{\circ} \mathrm{C}$ leads to drastic differences in the carrier density and mobility. The mobility falls rapidly from 23.37 to $3.5 \mathrm{~cm}^{2} / \mathrm{V} \mathrm{s}$ and the carrier density decreases from above to below the onset of metallic conductivity. Taking into account the initial low temperature $\left(300{ }^{\circ} \mathrm{C}\right)$, and the limited duration of the cooling process (less than $30 \mathrm{~min}$ ), the oxygen uptake during the cooling should be limited. As a result, a slight change of the oxygen composition (and in oxygen vacancy concentration) of the films induces large effects on the transport phenomena of the film. This result can be related to those reported in a recent publication [3]. Indeed, it has been demonstrated by using surface calculations and thickness-dependent Hall measurements that surface donors rather than defects dominate the conductivity of undoped $\mathrm{In}_{2} \mathrm{O}_{3}$ films [3]. This means that conductivity of $\operatorname{In}_{2} \mathrm{O}_{3}$ films is very sensitive to the precise oxygen composition, i.e. oxygen vacancies play the role of donors in this material.

\section{Conclusion}

Epitaxial indium oxide films with the cubic bixbyite structure were obtained by PED method on c-cut sapphire substrates at $10^{-2}$ mbar oxygen pressure at low growth temperatures from 200 to $500{ }^{\circ} \mathrm{C}$. Two distinct structural phases were evidenced in the films: an ordered bixbyite phase with the three-fold symmetry in the (111) plane, and, a disordered bixbyite phase with a six fold symmetry in the (111) plane. This is related to the specificities of the growth conditions which can induce a large disorder in the oxygen network of $\mathrm{In}_{2} \mathrm{O}_{3}$. While the optical transparency is high ( $>80 \%$ ) in the visible spectral range for all films, the electrical properties were tailored as a function of growth temperature. For films grown at $200{ }^{\circ} \mathrm{C}$ a metallic conductivity at room temperature and a metal-semiconductor transition at low temperature were evidenced. For the films grown at 400 and $500{ }^{\circ} \mathrm{C}$ the classical semiconductor behaviour was observed, the mobility decreasing with improvement in the crystalline quality of films. Moreover, the ordered bixbyite phase was found to favour a high carrier density and accordingly a lower resistivity in the films leading these epitaxial films as potential layers as substrates for the subsequent solar cells growth. Such results open the way to the optimisation of the growth conditions in order to obtain pure ordered bixbyite films with a very high carrier density, while preserving the high optical transparency, in view of their use as transparent conducting electrodes. The fact that such pure ordered bixbyite films could be obtained at low growth temperature $\left(<200{ }^{\circ} \mathrm{C}\right)$ would favour their use as transparent conducting layers to avoid the degradation of the solar cell junctions in photovoltaics.

\section{Acknowledgements}

M. Nistor would thank a grant of theRomanian National Authority for Scientific Research, CNCS-UEFISCDI, Project number 227 PN-II-ID-PCE-2011-3-0566. One of the Authors, W. Seiler would thank S. Fox and F. Dechelotte for enlightening discussions. The agreement on cooperation between INSP, Université Pierre et Marie Curie-Paris 6 and NILPRP Romania is acknowledged.

\section{Referencess}

[1] A. Facchetti, T.J. Marks (Eds.), Transparent Electronics From Synthesis to Applications, John Wiley \& Sons Ltd., United Kingdom, 2010.

[2] David S. Ginley, Hideo Hosono, David C. Paine (Eds.), Handbook of Transparent Conductors, Springer, New York Heidelberg Dordrecht London, 2011.

[3] S. Lany, A. Zakutayev, T.O. Mason, J.F. Wager, K.R. Poppelmeier, J.D. Perkins, J.J. Berry, D.S. Ginley, A. Zunger, Surface origin of high conductivities in undoped $\mathrm{In}_{2} \mathrm{O}_{3}$ films, Physical Review Letters 108 (2012) 016802.

[4] H. Ohta, M. Orita, M. Hirano, H. Tanji, H. Kawazoe, H. Hosono, Highly electrically conductive indium-tin-oxide thin films epitaxially grown on yttria-stabilized zirconia (100) by pulsed-laser deposition, Applied Physics Letters 76 (2000) 2740.

[5] K.H.L. Zhang, V.K. Lazarov, P.L. Galindo, F.E. Oropeza, D.J. Payne, H.H.C. Lai, R.G. Egdell, Domain matching epitaxial growth of $\mathrm{In}_{2} \mathrm{O}_{3}$ thin films on $\alpha-\mathrm{Al}_{2} \mathrm{O}_{3}$ (0001), Crystal Growth Design 12 (2012) 1000. 
[6] L. Kong, J. Ma, C. Luan, Z. Zhu, Q. Yu, Domain structure and optical property of epitaxial indium oxide film deposited on $\mathrm{MgO}(100)$ substrate, Surface Science 605 (2011) 977.

[7] Ch.Y. Wang, L. Kirste, F.M. Morales, J.M. Manuel, C.C. Röhlig, K. Köhler, V. Cimalla, R. Garcia, O. Ambacher, Growth mechanisms and electrical properties of epitaxial $\mathrm{In}_{2} \mathrm{O}_{3}$ films on sapphire, Journal of Applied Physics 110 (2011) 093712-7.

[8] F. Yang, J. Ma, X. Feng, L. Kong, Structural and photoluminescence properties of single-crystalline $\mathrm{In}_{2} \mathrm{O}_{3}$ films grown by metal organic vapor deposition, Journal of Crystal Growth 310 (2008) 4054-4057.

[9] Z.X. Mei, Y. Wang, X.L. Du, Z.Q.H. Zheng, J.F. Lia, Q.K. Xue, Z. Zhang, Growth of $\mathrm{In}_{2} \mathrm{O}_{3}$ single-crystalline film on sapphire (0001) substrate by molecular beam epitaxy, Journal of Crystal Growth 289 (2009) 686-689.

[10] K.H.L. Zhang, D.J. Payne, R.G. Palgrave, V.K. Lazarov, W. Chen, A.T.S. Wee, C.F. McConville, P.D.C. King, T.D. Veal, G. Panaccione, P. Lacovig, R.G. Egdell, Surface structure and electronic properties of $\operatorname{In}_{2} \mathrm{O}_{3}$ (111) single-crystal thin films grown on Y-stabilized $\mathrm{ZrO}_{2}$ (111), Chemistry of Materials 21 (2009) 4353-4355.

[11] Y.C. Liang, H.Y. Lee, Growth of epitaxial zirconium-doped indium oxide (222) at low temperature by rf sputtering CrystEngComm. 12 (2010) 3172-3176.

[12] W.H. Chi, K.Y. Yem, H.L. Su, S.C. Li, J.R. Gong, On the physical properties of $\operatorname{In}_{2} \mathrm{O}_{3}$ films grown on (0001) sapphire substrates by atomic layer deposition, Journal of Vacuum Science and Technology 29 (2011) 03A105-4.

[13] E.J. Tarsa, J.H. English, J.S. Speck, Pulsed laser deposition of oriented $\mathrm{In}_{2} \mathrm{O}_{3}$ on (001) InAs, MgO and yttria-stabilized zirconia, Applied Physics Letters 62 (1992) 2332-2334.

[14] A. Rogozin, M. Vinnichenko, N. Shevchenko, U. Kreissig, A. Kolitsch, W. Möller Real-time evolution of electrical properties and structure of indium oxide and indium tin oxide during crystalization, Scripta Materialia 60 (2009) 199-202.

[15] T.A. Gessert, Y. Yoshida, C.C. Fesenmaier, T.J. Coutts, Sputtered $\mathrm{In}_{2} \mathrm{O}_{3}$ and ITO thin films containing zirconium, Journal of Applied Physics 105 (2009) 083547-6-03A105-4

[16] M. Zhang, D.B. Buchholz, S.J. Xia, R.P.H. Chang, Twinned domains in epitaxial $\mathrm{ZnO} / \mathrm{SnO}_{2}$-cosubstituted $\mathrm{In}_{2} \mathrm{O}_{3}$ thin films, Journal of Crystal Growth 308 (2007) 376-381.

[17] M. Nistor, J. Perrière, C. Hebert, W. Seiler, Nanocomposite indium tin oxide thin films: formation induced by a large oxygen deficiency and properties, Journal of Physics Condensed Matter 22 (2010) 045006-7.

[18] E. Le Boulbar, E. Millon, J. Mathias, C. Boulmer-Leborgne, M. Nistor, F. Gherendi, N. Sbaï, J.B. Quoirin, Pure and Nb-doped $\mathrm{TiO}_{1.5}$ films grown by pulsed-laser deposition for transparent $p-n$ homojunction, Applied Surface Science 257 (2011) 5380-5383.

[19] S. Degoy, J. Jimenez, P. Martin, O. Martinez, A.C. Prieto, D. Chambonnet, C. Audry, C. Belouet, J. Perriere, Oxygen content of $\mathrm{YBaCuO}$ thin films, Physica C 256 (1996) 291-297.

[20] R. Perez-Casero, J. Perrière, A. Gutierrez-Llorente, D. Defourneau, E. Millon, W. Seiler, L. Soriano, Thin films of oxygen deficient perovskite phases, Physical Review B 75 (2007) 165317-7.

[21] M. Nistor, A. Petitmangin, C. Hebert, W. Seiler, Nanocomposite oxide thin films grown by pulsed energy beam deposition, Applied Surface Science 257 (2011) 5337-5340.

[22] E. Millon, M. Nistor, C. Hebert, Y. Davila, J. Perrière, Phase separation in nanocomposite indium tin oxide thin films grown at room temperature, Journal of Materials Chemistry 22 (2012) 12179-12185.

[23] S. Lany, A. Zunger, Dopability, intrinsic conductivity and nonstoichiometry of transparent conducting oxides, Physical Review Letters 98 (2007) 045501-4.
[24] K.H.L. Zhang, A. Walsh, C.R.A. Catlow, V.K. Lazarov, R.G. Egdell, Surface energies control the self-organization of oriented $\mathrm{In}_{2} \mathrm{O}_{3}$ nanostructures on cubic zirconia, Nano Letters 10 (2010) 3740-3746.

[25] J. Narayan, K. Dovidenko, A.K. Sharma, S. Oktyabarsky, Defects and interfaces in epitaxial $\mathrm{ZnO} / \alpha-\mathrm{Al}_{2} \mathrm{O}_{3}$ and $\mathrm{AlN} / \mathrm{ZnO} / \alpha-\mathrm{Al}_{2} \mathrm{O}_{3}$ heterostructures, Journal of Applied Physics 84 (1998) 2597-2601.

[26] P.R. Willmott, R. Timm, J.R. Huber, RHEED analysis of interface growth modes of TiN on Si (001) produced by crossed beam laser ablation, Applied Surface Science 127-129 (1998) 105-110.

[27] J. Guo, H.L.M. Chang, D.J. Lam, Substrate surface step effects on microstructure of epitaxial films, Applied Physics Letters 61 (1992) 3116-3117.

[28] B. Lacroix, F. Paumier, R.J. Gaboriaud, Crystal defects and related stress in $\mathrm{Y}_{2} \mathrm{O}_{3}$ thin films: origin, modeling and consequence on the stability of the C-type structure, Physical Review B 84 (2011) 014104-12.

[29] A. Walsh, J.L.F. Da Silva, S.H. Wei, C. Korber, A. Klein, L.F.J. Piper, A. De Masi, K.E. Smith, G. Panaccione, P. Torelli, D.J. Payne, A. Bourlange, R.G. Egdell, Nature of the band gap of $\operatorname{In}_{2} \mathrm{O}_{3}$ revealed by first principles calculations and Xray spectroscopy, Physical Review Letters 100 (2008) 167402-4.

[30] A. Bourlange, D.J. Payne, R.G. Egdell, J.S. Foord, P.P. Edewards, M.O. Jones, A. Schertel, P.J. Dobson, J.L. Hutchinson, Growth of $\mathrm{In}_{2} \mathrm{O}_{3}(100)$ on Y-stabilized $\mathrm{ZrO}_{2}(100)$ by O-plasma assisted molecular beam epitaxy, Applied Physics Letters 92 (2008) 092117-3.

[31] F. Fuchs, F. Bechstedt, Indium-oxide polymorphs from first principles: quasiparticles electronic states, Physical Review B 77 (2008) 155107-10.

[32] T. Koida, M. Kondo, High electron mobility of indium oxide grown on yttriastabilized zirconia, Journal Applied Physics 99 (2006) 123703-6.

[33] K. Ellmer, R. Mientus, Carrier transport in polycrystalline ITO and ZnO:Al II: The influence of grain barriers and boundaries, Thin Solid Films, 516, 5829-5835.

34] H. Nakazawa, Y. Ito, E. Matsumoto, K. Adachi, N. Aoki, Y. Ochiai, The electronic properties of amorphous and crystalllized $\mathrm{In}_{2} \mathrm{O}_{3}$ films, Journal Applied Physics 100 (2006) 093706-8.

[35] N.F. Mott, Conduction in Non-Crystalline Materials, Clarendon, Oxford, 1993.

[36] R.P. Panguluri, P.K. Kharel, C. Sudakar, R. Naik, R. Suryanarayanan, V.M. Naik A.G. Petukhov, B. Nadgorny, G. Lawes, Ferromagnetism and spin-polarized charge carriers in $\mathrm{In}_{2} \mathrm{O}_{3}$ thin films, Physical Review B 79 (2009) 165208-6.

37] X.D. Liu, E.Y. Jiang, D.X. Zhang, Electrical transport properties in indium tin oxide films prepared by electron-beam evaporation, Journal of Applied Physics 104 (2008) 073711-5.

[38] M. Nistor, F. Gherendi, N.B. Mandache, C. Hebert, J. Perriere, W. Seiler, Metalsemiconductor transition in epitaxial ZnO films, Journal of Applied Physics 106 (2009) 106710-7.

[39] V. Bhosle, A. Tiwari, J. Narayan, Metallic conductivity and metalsemiconductor transition in Ga-doped $\mathrm{ZnO}$, Applied Physics Letters 88 (2006) 032106-3.

[40] P.A. Lee, T.V. Ramakrishnan, Disordered electronic systems, Reviews of Modern Physics 57 (1985) 287-337.

[41] G. Herranz, F. Sanchez, B. Martinez, J. Fontcuberta, MV. Garcia-Cuenca, C. Ferrater, M. Varela, P. Levy, Weak localization effects in some metallic perovskites, European Physical Journal B 40 (2004) 439-444.

[42] O.M. Berengue, C.A. Amorim, H. Kanimura, A.J. Chiquito, E.R. Leite, Oxygeninduced metal-insulator-transition on single crystalline metal oxide wires, Journal of Applied Physics 111 (2012) 013713-6.

[43] T. Kamiya, K. Nomura, H. Hosono, Origin of definite Hall voltage and positive slope in mobility-donor density relation in disordered oxide semiconductors, Applied Physics Letters 96 (2010) 122103-3. 